\title{
Oxidative Stress in Human Autoimmune Joint Diseases
}

\author{
Martina Škurlová \\ Department of Normal, Pathological, and Clinical Physiology, \\ Third Faculty of Medicine, Charles University in Prague, \\ Czech Republic
}

\section{Introduction}

Living with oxygen is basically unsafe, but vital. During evolution, oxygen originally a waste product of the metabolism in primitive unicellular organisms became normal product of the metabolism in higher animal species involving humans. Even when oxidative reactions are toxic, and destructive, they are tolerated by all organisms to some extent. The fact has opened the discussion about efficiency of antioxidant mechanisms. The classical enzyme antioxidant defence alone does not explain high tolerance of the organism for oxygen. Moreover, enzyme antioxidant mechanisms are not hundred percent effective in preventing oxidation what allows oxidative damage to continue.

The pathogenesis of autoimmune joint inflammatory diseases is related to activation of native immune system. At site of inflammation, activated neutrophils and macrophages consume large amounts of oxygen, whose corollary is the increase of reactive oxygen species (ROS) production. There are several mechanisms how oxidative stress is involved into the pathogenesis of autoimmune joint inflammatory diseases. Excess production of ROS in the joint area encourages process of re-oxygenation, which then promotes joint inflammation. ROS further inhibit connective tissue cell proliferation, in some cases ROS have been shown to induce cell death to these cells inducing apoptosis.

\section{Oxidative stress}

\subsection{Biology of oxidative stress}

Cellular responses to oxidative stress depend on the cellular redox status. When the oxidants' level does not exceed the redox capacities in a cell, oxidants are beneficial to the cell controlling cellular functions such as signal transduction. In contrast, when the cellular antioxidant capacity is insufficient, the production of oxidants exceeds the capacity to neutralize them (Hitchon \& El- Gabalawy, 2004). Insufficient oxidative defence mechanisms shift the balance between oxidants and antioxidants in the direction of oxidants leading to oxidative stress. Insufficient oxidative defence mechanisms result from depletion of enzymatic (e.g., superoxide dismuthase, catalase, glutathione peroxidase), and nonenzymatic (e.g., glutathione, vitamins A, C, and E, and selenium) antioxidants (Hovatta et al., 2010). The pro-oxidant conditions of the 'internal milieu', due to low redox status of the 
cell led to a new definition of oxidative stress. Oxidative stress is defined as " disruption between ROS production and elimination leading to their enhanced steady- state in the body" (Lushchak, 2011).

Reactive oxygen species destroy not only intracellular components, but also cell membranes, and extracellular components. ROS modify proteins by oxidation, nitrosylation, nitration or chlorination of specific amino acids, leading to their impaired biological activity, changes in protein structure and accumulation of damaged proteins in the tissue. During lipid peroxidation, which is a marker of oxidative stress, polyunsaturated fatty lipids are oxidized and produce lipid peroxyl radicals that in turn up-regulate oxidation, and cell membrane damage (Hitchon \& El- Gabalawy, 2004). Genotoxic effects of oxidative stress involve direct breakage of DNA and DNA repair mechanisms. Oxidative stress may also cause cell death. Cellular content containing oxidized molecules when released into the extracellular environment may contribute to the exacerbation of synovial inflammation as newly formed ROS and degradation products form a vicious inflammatory circle (Henrontin et al., 2003).

\section{Reactive oxidant species}

Free radicals are very reactive chemical species that have unpaired valence shell electrons in their outer orbitals (Afonso et al., 2007). Highly reactive and partly reduced oxygen metabolites are a by-product of oxidative phosphorylation process, which takes part in mitochondria. These metabolites called ROS include oxygen radicals [superoxide $\left(\mathrm{O}_{2}{ }^{\circ}-\right)$, hydroxyl $(\mathrm{HO} \cdot)$, peroxyl $\left(\mathrm{O}_{2} \mathrm{R}^{*}\right)$, and alkoxyl $\left.\left(\mathrm{OR}^{\bullet}\right)\right]$ and certain non radicals that are either oxidizing agents or are easily converted into radicals, such as hypochlorous acid ( $\mathrm{HOCl})$, ozone $\left(\mathrm{O}_{3}\right)$, singlet oxygen $\left({ }^{1} \mathrm{O}_{2}\right)$, and hydrogen peroxide $\left(\mathrm{H}_{2} \mathrm{O}_{2}\right)$. Other oxidants, generated by interactions with these molecules, include reactive nitrogen species (RNS), as an example nitric oxide (NO), peroxynitrite (ONOO-).

\subsection{Generation of reactive oxidant species}

Generation of ROS is generally cascade of reactions that starts with the production of $\mathrm{O}_{2}{ }^{-}$. Superoxide rapidly dismutates to $\mathrm{H}_{2} \mathrm{O}_{2}$ either spontaneously, particularly at low $\mathrm{pH}$, or catalyzed by superoxide dismutase (SOD) enzyme. Other steps in the cascade of ROS generation include the reaction of $\mathrm{O}_{2}{ }^{-}$- with $\mathrm{ON} \cdot$ to form $\mathrm{ONOO}$-, the peroxidase-catalyzed formation of $\mathrm{HOCl}$ from $\mathrm{H}_{2} \mathrm{O}_{2}$, and the iron-catalyzed Fenton reaction leading to the generation of $\mathrm{HO}^{\bullet}$. Hydroxyl radical is one of the most reactive oxygen radicals. In biologic systems, the $\mathrm{HO}^{*}$ is formed by the reaction between $\mathrm{H}_{2} \mathrm{O}_{2}$ and iron or copper in a low valence state. The oxidized halogens are almost as diverse group of reactive oxidants as are the free radicals. They consist of $\mathrm{HOCl}$ and the vast number of chloramines. Chloramines can be produced from the reaction of $\mathrm{HOCl}$ with the many amines that are found in biological systems. Like $\mathrm{HOCl}$, the chloramines are oxidizing species. Chloramine $\left(\mathrm{NH}_{2} \mathrm{Cl}\right)$ is formed by the reaction of $\mathrm{HOCl}$ with ammonia $\left(\mathrm{NH}_{3}\right)$. The reaction of $\mathrm{HOCl}$ with amino acids leads through chloramines to aldehydes. Altogether, the oxidized halogens represent probably the most important microbicidal oxidants produced by neutrophils. Oxygen $\left(\mathrm{O}_{2}\right)$ alone is a diradical with two unpaired electrons. There is also a much more reactive form of oxygen known as $1 \mathrm{O}_{2}$, in which those two electrons are paired. The $1 \mathrm{O}_{2}$ is produced by neutrophils, which manufacture it by the reaction between $\mathrm{H}_{2} \mathrm{O}_{2}$ and an oxidized halogen. 
Reactive nitrogen species are produced by phagocytes during the reaction of $\mathrm{NO}$ with $\mathrm{O}_{2}{ }^{-}$, and other oxidizing species. The first characterized of these species is ONOO-, formed in a reaction between $\mathrm{ON}^{\cdot}$ and $\mathrm{O}_{2}{ }^{-}$, , both of which are free radicals. Peroxynitrite then undergoes a secondary reaction to produce an agent that is able to nitrate tyrosine. The precise composition of the agent is not known, but several candidates have been proposed. Among them are various derivatives of ONOO- Major cellular sites of ROS generation include the mitochondria, and non- mitochondrial membrane bound enzyme systems (Babior, 2000).

\subsection{Reactive oxidant species in the joint tissue}

Articular cartilage is a unique tissue for its constituent cells, the chondrocytes, which maintain the cartilage matrix through their continual synthesis and degradation. The environment is avascular, hyperosmotic and acidic. Cartilage cells are synoviocytes, and chondrocytes. Chondrocytes display a metabolism adapted to anaerobic conditions. Synoviocytes supply the avascular cartilage tissue with nutrients via synovial fluid. Because cartilage is an avascular environment, the oxygen tension in the area is usually low. In pathological conditions, like inflammation, oxygen tension is subject of fluctuations. These variations of oxygen tension force chondrocytes to produce reactive species. The main reactive species produced by chondrocytes are $\mathrm{O}_{2}{ }^{\circ}$ - radical, and $\mathrm{NO}$ that generate other derivative radicals, including ONOO- and $\mathrm{H}_{2} \mathrm{O}_{2}$ (Hiran et al., 1997; Stefanovic- Racic et al., 1997). The effects of free radicals on articular cartilage are dual. "Chondrocyte- derived" free radical levels are important for the maintenance of ion homeostasis. Natrium hydrogen $\left(\mathrm{Na}^{+}\right.$ - $\mathrm{H}^{+}$) - exchanger (NHE- activity) and free radical levels exhibit a significant positive correlation. How exactly highly reactive species alter ion transport is not known, although interference with protein phosphorylation is possible (Gibson et al., 2008).

Except beneficial effect free radicals may have on articular cartilage when exceed in a cell, free radicals damage both chondrocytes, and extracellular matrix (ECM) components of articular cartilage. Free radicals shift the redox balance in articular cartilage in direction of oxidants. Hypochlorous acid, singlet oxygen, and peroxynitrite radicals balance the ascorbate, an antioxidant vitamin, from cartilage (Hajdigogos et al., 2003).

ROS and RNS damage articular cartilage directly or indirectly by up- regulating the mediators of the ECM degradation. Reactive oxygen/ nitrogen species, e.g. ONOO-, also have been shown to degrade aggrecan, a major component of ECM, and this degradation is one of the initial events in the process of cartilage destruction (Billinghurst et al., 1997). The incidence of sulfated glycosaminoglycans (GAGs) reflects the ratio of aggrecan degradation in the cartilage.

In seeking for a role of oxidative radicals in cartilage metabolism, it has been noted that endogenously generated NO suppresses the biosynthesis of aggrecan, a major macromolecular component of the cartilaginous matrix (Cao et al., 1997). Furthermore, it was discovered that oxygen radicals fragment hyaluronan and chondroitin sulphate (Kennett \& Davies, 2009).

Collagen, which provides tensile strength and forms a network that resists the swelling pressure of aggrecan- hyaluronate aggregates, can be altered directly by oxygen radicals. Free radicals prime collagen to proteolytic enzymes. Incubation of cartilage slices with 
xanthine-oxidase- generated $\mathrm{O}_{2}{ }^{\bullet}$ - anion degrades type I collagen and fibril formation by this collagen. Hydroxyl radical in the presence of oxygen fragments collagen into small peptides. The cleavage seems to be specific to proline or 4- hydroxyproline residues (Monboisse \& Borel, 1992). Interestingly, free radicals may destruct collagen synthesis indirectly. NO inhibits collagen synthesis via interleukin-1 (IL-1) (Cao et al., 1997). $\mathrm{H}_{2} \mathrm{O}_{2}$ inhibits cartilage proteoglycan synthesis interfering with adenosine triphosphate (ATP) synthesis, in part by inhibiting the glycolytic enzyme glyceraldehyde-3-phosphate dehydrogenase in chondrocytes. ONOO- and $\mathrm{HOCl}$ may facilitate cartilage damage by inactivating tissue inhibitor of metalloproteinases (TIMPs). TIMP-1 inhibits stromelysins, collagenases and gelatinases (Henrontin et al., 2003). Moreover it was observed, that treatment of chondrocytes with the NO-producing agent, S-nitroso-N-acetylpenicillamine, up- regulates the collagenase mRNA levels, which is one of MMPs (Lo et al., 1998).

Exposure of the chondrocytes to $\mathrm{H}_{2} \mathrm{O}_{2}$ inhibits proteoglycan synthesis (Henrontin et al., 2003). Chondrocytes in arthritic cartilage respond poorly to insulin- like growth factor 1 (IGF-1) what may lead to abrogation of cartilage repair. In this context, ROS may participate in reducing the capacity of chondrogenic precursor cells to migrate and proliferate within joint area. Nitric oxide radical was also demonstrated to inhibit chondrocyte migration and attachment to fibronectin via modification of the actin cytoskeleton. Chondrocytes produce high levels of NO, which is a mediator of anti- proliferative effects of IL-1 in these articular cells (Blanco \& Lotz, 1994). In addition, it was discovered that IL-1 induces apoptosis to chondrocytes via NO. Combination of IL-1 with the radical scavengers like N-acetyl cysteine, dimethyl sulfoxide, or 5, 5'-dimetylpyrroline 1-oxide induced apoptosis, which was inhibited in a dose dependent manner by the NO synthase inhibitor N-monomethyl Larginine (Blanco et al., 1995). Chondrocyte death, determined as the percentage of empty lacunae in articular cartilage, was completely blocked in p47phox-/- mice confirming the "Nicotinamide adenine dinucleotide phosphate" (NADPH)- oxidase" driven oxygen radical production in mediating these effects (Lem van Lent et al., 2005).

Synoviocytes are the second kind of articular cells. These cells consume larger amount of oxygen when compared to chondrocytes (Schneider et al., 2005). An indirect evidence of oxidative stress in synoviocytes is the incidence of antioxidant enzymes such as superoxide dismutase, glutathione peroxidase and catalase in these cells (Mattey et al., 1993). Oxidative stress makes synoviocytes to undergo a cell death of an apoptotic nature (Galleron et al., 1999). The ROS scavenger system of synoviocytes protects chondrocytes from toxic effects of free radicals. In a co-culture of these cells synoviocytes reduced toxic effects of $\mathrm{H}_{2} \mathrm{O}_{2}$ on chondrocyte cell damage (Kurz et al., 1999). NO is the primary inducer of apoptosis in human articular chondrocytes (Blanco et al., 1995). NO- mediated chondrocyte cell death requires generation of additional reactive species like ONOO- and $\mathrm{O}_{2}^{--}$(Del Carlo Jr. \& Loeser, 2002).

Joint fluid is produced as a transudate of plasma from synovial cells and provides nutrition to the articular cartilage by diffusion of oxygen and other molecules. The primary catalytic antioxidant of the joint fluid is the extracellular SOD (Regan et al., 2008). SOD type III accounts for $80 \%$ of the enzyme's activity in the joint fluid (Afonso et al., 2007). Glycosaminoglycans (long-chain polysaccharides) are major components of the extracellular matrix, glycocalyx, and synovial fluid. Modifications to these materials are linked to multiple human pathologies including autoimmune diseases. Hyaluronan and chondroitin 
sulfate are extensively depolymerized by hydroxyl and carbonyl radicals, which may be formed from ONOO.. Polymer fragmentation is shown to be dependent on the radical flux (Kennett \& Davies, 2009). NO, and $\mathrm{O}_{2 .-}$ inhibit type II collagen and proteoglycans synthesis and the sulfation of newly synthesized GaGs (Hickery \& Bayliss, 1998).

\section{Inflammatory synovitis: May oxidative stress be a cause?}

\subsection{ROS in inflammatory synovium}

In autoimmune joint diseases systemic inflammation exists long before it exerts local effects on synovial membrane. At one point, systemic inflammation is translocated into synovium where it initiates the inflammatory response often leading to oxidative burst. Oxidative burst in rheumatoid joints is a result of the activation of innate immune system cells. Activated phagocytic cells such as neutrophils, and macrophages both produce free radicals in the joint area. Activated phagocytes produce reactive oxidants by enzymes: the NADPH- oxidase, and the nitric oxide synthase (NOS). Mechanism of free radicals production differs between these cell groups. While macrophages are stimulated by the "NADPH- oxidase" system to produce free radicals, the presence of NOS accompanied by the NADPH- oxidase is necessary for neutrophils to secrete free radicals. RA neutrophils also generate enhanced amount of ONOOby NOS (El Benna et al., 2002). Chemiluminescence assays demonstrated significant activation of the neutrophil myeloperoxidase $\mathrm{H}_{2} \mathrm{O}_{2}$ system in synovial fluids from patients with $\mathrm{RA}$ further suggesting that oxidative stress may contribute to the cyclic, self- perpetuating nature of rheumatoid inflammation. ROS, produced by activated phagocytes alters the antigenic behaviour of immunoglobulin $\mathrm{G}$ (IgG). Radical-exposed IgG is able to bind rheumatoid factor and results in the generation of C3alpha complement component. This reaction may be selfperpetuating within the rheumatoid joint, suggesting that free radicals play a role in the chronicity of rheumatoid inflammation (Newkirk et al., 2002).

Pro-inflammatory cytokines' presence and activity undoubtedly subjects to rheumatoid synovitis governing a variety of pathological processes including cell activation, cell proliferation, tissue resorption and chemotaxis (Schett et al., 2000). Experimental evidence confirms cytokine- induced oxidative stress in rheumatoid synovium. Thioredoxin, a cellular catalyst induced by oxidative stress, is found in high amounts in RA synovial cells and tissue. Thioredoxin acts as a co- factor for tumor necrosis factor- alpha (TNF- $\alpha$ ) induced synthesis of interleukins (IL-6 and IL-8) in synovial fibroblastlike cells (Yoshida et al., 1999). Edaravone, which is a clinically available antioxidant, suppresses IL-1 $\beta$ - induced synovial cells proliferation and migration under in vitro conditions (Arii et al., 2006). Nacetylcytein, a known thiol antioxidant, abrogated L-6 - induced proliferation of RA patients synovial fibroblasts (Ji-Yeon et al., 2000).

ROS are documented as mediators of synovial inflammation. Excessive production of ROS at the site of inflammation contributes to the inflammatory process in general, by induction of the expression of adhesion molecules, pro-inflammatory cytokines, and chemoattractants. Furthermore, ROS can directly increase tissue destruction through inactivation of the major inhibitor of degrading enzymes, $\alpha 1$-antiproteinase, which subsequently leads to the activation of extracellular matrix-degrading metalloproteinases (MMPs) (Maurice et al., 1997). 3-nitrotyrosine (3- NT) has been identified as a stable end product and marker of 
inflammation and RNS production. Nitrated proteins are generated in inflamed tissues by inflammatory cells producing ONOO-, a naturally occurring nitrating agent. A study by Khan \& Siddiqui (2006) further investigated the binding characteristics of naturally occurring antibodies to 3- NT present in synovial fluid. Antibodies to 3- NT were found higher in the synovial fluid of RA patients.

Ex-vivo cultured rheumatoid synovium produces a significant amount of nitrite, and the addition of $\mathrm{N}$ - methylarginine (L-NMMA) significantly inhibits $\mathrm{NO}$ production. In vitro study revealed that NO production from freshly isolated synovial cells was up- regulated by stimulation with a combination of IL-1 $\beta, \mathrm{TNF}-\alpha$ and lipopolysaccharide. Inducible NOS expression was induced when human chondrocytes were stimulated with IL-1 $\beta$, TNF- $\alpha$ or endotoxin in a dose- and time-dependent manner. Inflammatory reaction in the synovium of RA patients could be augmented by the autocrine or other cytokine-induced production of IL- 6 with subsequent generation of ROS in the synoviocytes. Fibroblast- like synoviocytes proliferation by IL-6 was inhibited by N- acetylcysteine. Oxidative stress of RA synovial tissue can cause DNA damage and suppress the DNA mismatch repair (MMR) system in cultured synoviocytes. DNA MMR enzyme expression is greatest in the synovial intimal lining layer, where maximal oxidative stress in RA occurs (Šimelyte et al., 2004).

\subsection{Cycles of hypoxia/ reoxygenation in inflammatory synovium}

Angiogenesis in the synovial membrane is an important early step in pathogenesis of RA, in the perpetuation of the disease and may precede other pathological features. Elevated levels of pro-angiogenic factor, the vascular endothelial growth factor VEGF, are expressed in synovium, synovial fluids, and serum of RA patients. An increased VEGF level in RA is responsible for subsequent joint destruction. The synovium of RA is hypoxic as a result of synovial tissue proliferation outpacing in angiogenesis. Hypoxia is a potent inducer of cytokines, matrix degrading enzymes, angiogenic factors that play a central role in the inflammatory response. Hypoxia- inducible factor- $1 \alpha(\mathrm{HIF}-1 \alpha)$ is a key transcription factor which is highly inducible by hypoxia and expressed predominantly in synovium of RA. Expression of HIF-1 $\alpha$ is critical for joint inflammation. RA synovial fluids are hypoxic, acidic with low glucose and elevated lactate concentrations. This biochemical profile is indicative of a chronically hypoxic microenvironment that compensates by anaerobic metabolism. The oxygen partial pressure $\left(\mathrm{pO}_{2}\right)$ is extremely low in RA synovial fluids, and correlates with elevated plasma levels of lactate. Inflamed synovitis is a hallmark of RA which is hypoxic in nature (Shankar et al., 2009). The biological basis of this process relates to hypoxia- inducible factor (HIF). The response of mammalian cells to hypoxia is mediated partly through stabilization of certain transcription factors including HIF-1 and HIF-2. These oxygen sensitive transcription factors are multifunctional. Firstly, they program the cells to anaerobic metabolism, secondly, they enhance cell survival by inhibiting apoptosis, and thirdly they improve the supply of oxygen by promoting angiogenesis and increase oxygencarrying capacity. In view of the crucial role of HIF-1 in cellular adaptation to hypoxia, its regulation needs to be rapidly responsive to changes in the cellular oxygen supply. Inhibition of degradation is the primary mechanism by which hypoxia directly regulates HIF- $1 \alpha$. In the absence of oxygen critical step of degradation process of HIF- $1 \alpha$, the hydroxylation of proline and asparagine residues, becomes rate limiting, thus preventing HIF-1 $\alpha$ from being degraded and leaving it free to bind to its constitutively expressed 
partner HIF-1 $\beta$. In rheumatic patients, joint movement in a ratio of normally functional joint increases the $\mathrm{pO}_{2}$ leading to re-oxygenation. In RA cycling transient episodes of hypoxia/reoxygenation increase levels of ROS. Increased mitochondrial ROS levels stabilize the transcription factor HIF- $1 \alpha$ (Chandel et al., 2000). Of particular relevance to RA was the marked attenuation of synovitis and articular damage in an adjuvant arthritis model when HIF- $1 \alpha$ was absent. In RA synovitis, HIF-1a protein accumulates and translocates to the nucleus and directly activates transcription of pro-angiogenic factor like VEGF. VEGF is highly inducible by hypoxia which occurs in the inflamed joints of RA. The HIF-1 $\alpha$ translocates and binds to core DNA motif in the hypoxia responsive elements (HRE) which are associated with target genes such as VEGF and induces its gene expression and thereby angiogenesis. HIF- $1 \alpha$ is expressed abundantly by macrophages in most rheumatoid synovia, predominantly close to the intimal layer but also in the subintimal zone (Hollander et al., 2001). The synovial expression of HIF-1 $\alpha$ also showed a mixed nuclear and cytoplasmic pattern mostly seen in lining cells, stromal cells, mononuclear cells, and blood vessels (Giatromanolaki et al., 2002). The number of HIF-1 $\alpha$-positive cells correlated strongly with the number of blood vessels in RA synovial tissue and with inflammatory endothelial cell infiltration (blood vessels), cell proliferation (Ki67) and the synovitis score (Brouwer et al., 2009). Reduction in the degradation rate of HIFs (HIF- $1 \alpha$, and HIF- $2 \alpha$ ) as occurs under hypoxic stress throughout arthritis, results in increased steady- state level of HIFs proteins and up-regulation of the neo- angiogenic process. Neo-angiogenic VEGF/ KDR pathway was shown persistently increased in RA, as indeed was microvessel density and the expression of PD- ECGF, irrespective of the extent of HIF expression (Giatromanolaki et al., 2002). The direct link exists between accumulation of HIFs and overexpression of VEGF in RA. Neo-angiogenesis contributes to pathogenesis of RA encouraging synovitis, pannus formation and articular cartilage destruction. Concluding, the HIF seems to be a promising factor that targets both synovitis and angiogenesis in RA.

\section{Oxidative stress in human autoimmune joint diseases}

\subsection{Rheumatoid arthritis}

Rheumatoid arthritis (RA) is a systemic autoimmune inflammatory disease primarily affecting synovial membranes of joints. Pathogenesis of RA is a multistep process where cellular and humoral interactions mediated by lymphocytes ( $\mathrm{T}$ and $\mathrm{B}$ cells) and non hematopoietic cells like fibroblasts, connective tissue cells, and bone cells play a role. At site of inflammation, activation of $\mathrm{T}$ cells and macrophages leads to a large increase in oxygen consumption, whose corollary is increased release of ROS (Afonso et al., 2007). Both, hematopoietic, and connective tissue cells are subject of oxidative stress process in arthritis.

\subsubsection{Hematopoietic cells and tissue as oxidative stress targets in RA}

Activity of NADPH- oxidase is enhanced in circulating neutrophils and monocytes of RA patients. These phagocytic cells synthesize two- to eight- fold higher amounts of $\mathrm{O}_{2}{ }^{-}$- when compared to healthy controls. Production rates of $\mathrm{O}_{2}{ }^{\circ}$ - in neutrophils and monocytes from rheumatic patients positively correlate with the plasma levels of TNF- $\alpha$ (Miesel et al., 1996). Other parameters of oxidative stress like decrease in neutrophil SOD activity and an increase in the levels of "loose" iron in the plasmalemma of RA neutrophils and monocytes 
were also observed (Ostrakhovitch \& Afanas'ev, 2001). A characteristic feature of RA ROSproducing neutrophils is their functional state. The production of $\mathrm{O}_{2}{ }^{\circ}$ - by blood neutrophils from RA patients in response to $\mathrm{N}$-formyl-methionylleucyl-phenylalanine, a stimulatory agent, was greater in arthritic than control blood neutrophils (Eggleton et al., 1995). The study suggested that stimulated sub-population of neutrophils are source of ROS in arthritis.

\subsubsection{Connective cells and tissue as oxidative stress targets in RA}

Studies of RA synovial fluid (SF) and tissue have demonstrated oxidative damage to the tissue. Signs of oxidative stress such as DNA oxidative damage, and lipid peroxidation are present in the inflammatory synovium of RA patients. Immunohistochemical analysis revealed increased staining of 8- oxo- 7,8- dihydro- 2'-deoxyguanine, a marker of DNA oxidative damage, and increased staining of 4-hydroxy-2-nonenal in the lining and sublining layers of the RA inflammatory synovium (Šimelyte et al., 2004). Furthermore, it was shown that increased lipid peroxidation damage in RA inflammatory synovium is proportional to the levels of hypoxia in the joint, disease activity and angiogenic marker expression (Biniecka et al., 2009). Synovial fluids macrophages produce increased amounts of $\mathrm{O}_{2}{ }^{-}$. Also neutrophils from synovial fluids of rheumatic patients generate increased amounts of $\mathrm{O}_{2}{ }^{-}$- possibly because of their exposure to cytokines present in synovial fluids (Hitchon \& El-Gabalawy, 2004). Chronic oxidative stress contributes to functional hyporesponsiveness of synovial T lymphocytes. The impaired mitogenic responses of SF T lymphocytes correlated with a significant decrease in the levels of the intracellular redoxregulating agent glutathione (GSH) (Maurice et al., 1997).

Indirect evidence for ROS implication in cartilage degradation comes from the presence of lipid peroxidation products, nitrite, nitrotyrosine, a nitrated type II collagen peptide, modified low-density lipoprotein (LDL) and oxidized IgG in the biological fluids of patients with arthritis. Furthermore, nitrotyrosine, nitrated proteins and oxidized LDL (ox-LDL) have been found to be accumulated in cartilage of arthritic patients demonstrating the direct implication of ROS in some joint diseases. Rheumatoid arthritis is characterized by irreversible damage to the cartilage matrix caused by enzymatic degradation of the proteins, e.g., collagen type II (CII), and proteoglycans of cartilage (e.g., aggrecan) (Billinghurst et al., 1997). As a result of the breakdown of the proteins and proteoglycans, CII degradation products and sulfated glycosaminoglycans (GAGs) appear in SFs of the affected joints. The level of GAGs in SF indicates the extent of proteoglycan degradation (Lark et al., 1997). Hydrogene peroxide, and singlet oxygen accelerate bone resorption by osteoclasts. Osteoclasts generate ROS through "NADPH- oxidase dependent mechanisms". Studies involving assays of nitrotyrosine residues in synovial tissues from patients with RA or exposure of chondrocytes to synthetic peroxynitrite in vitro have established that combination of the $\mathrm{O}_{2}$ - anion to nitric oxide (NO) causes cartilage damage (Abramson et al., 2001).

The cytokine network is involved in the pathogenesis of RA. IL-1 is a key mediator of bone resorption and cartilage destruction in arthritis. The cytokine activates bone resorption through its effects on osteoclast differentiation and activation. IL-1 destructs cartilage by stimulating release of MMPs from fibroblasts and chondrocytes. Neutralizing ROS activity significantly attenuated IL-1- induced collagenase gene expression in bovine chondrocytes (Lo et al., 1998). 
In RA oxidative stress also features by oxidation of low- density lipoproteins (LDL). Oxidized LDLs promote inflammatory changes including local up- regulation of adhesion molecules and chemokines.

RA tissue has evidence of microsatellite instability reflecting ongoing mutagenesis. Such mutagenesis is normally corrected by DNA repair systems including the mismatch repair system, which is defective in RA, probably due to oxidative stress.

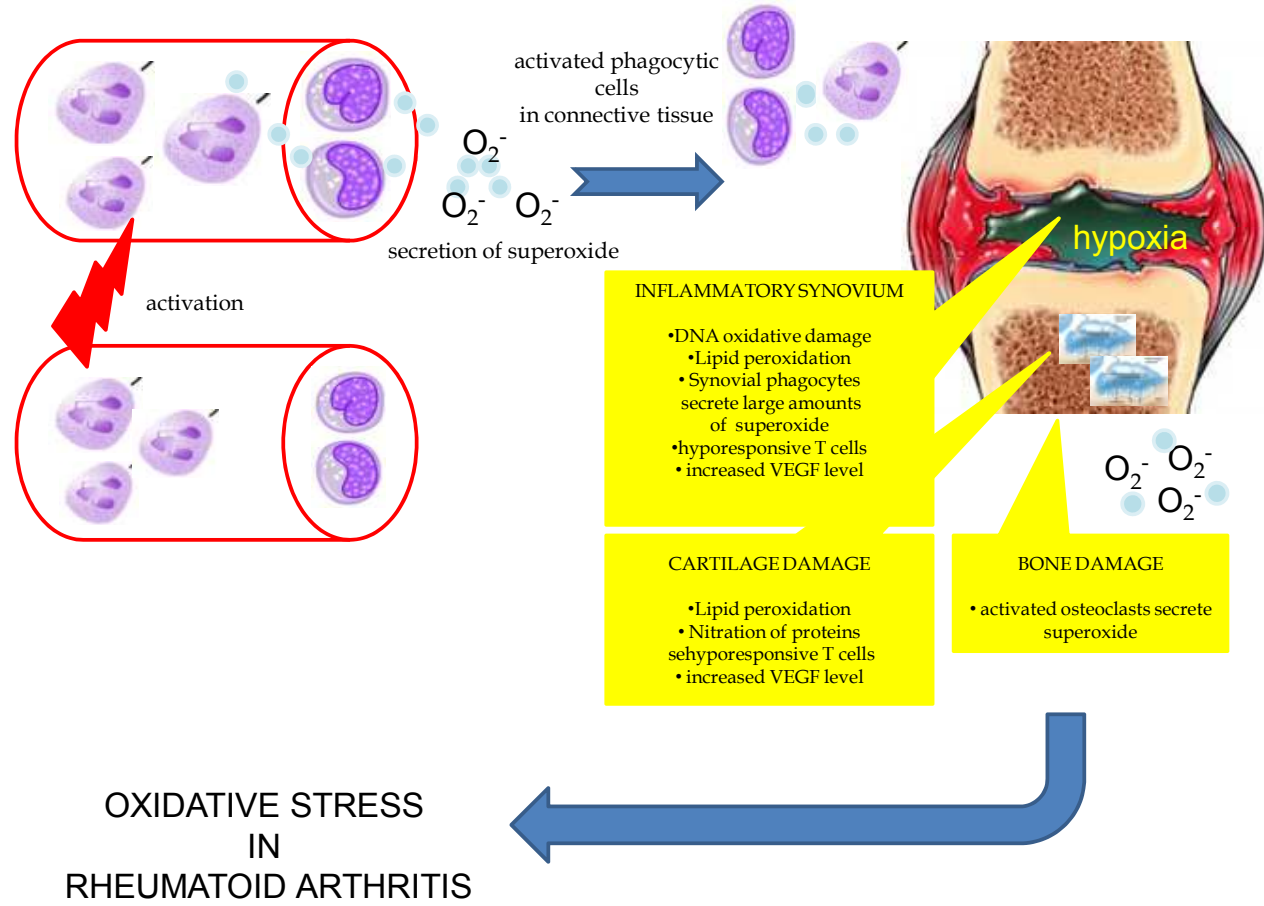

Fig. 1. Connective tissue and cells as targets of oxidative stress in rheumatoid arthritis.

\section{Systemic lupus erythematosus}

Systemic lupus erythematosus (SLE) is a prototype autoimmune, multisystem and multifactorial disease characterized by the presence of auto-antibodies to a variety of nuclear antigens such as DNA and histones, as well as protein antigens and protein-nucleic acid complexes. The initial immunizing antigen(s) that drive the development of SLE are unknown, but characteristics of the immune response in SLE suggest that it is an antigendriven condition. Multiorgan inflammatory lesions also involve the joints. Immune complex deposits in the synovium are associated with mild inflammation and cartilage destruction is seldom severe. The arthritis of SLE is described as non-destructive and non-deforming. Immune complex deposits in the synovium trigger inflammatory reaction, which led continuously to cartilage destruction (Khan \& Siddiqui, 2006). Free radicals synthesize autoantigens, which contribute to disease development. Oxidative stress and inflammation 
are interrelated in SLE. Malondialdehyd (MDA) levels positively correlated with levels of interferon- $\gamma$ (INF- $\gamma$ ), and interleukin- 12 (IL- 12) in lupus disease (Shah et al., 2010).

\subsection{Hematopoietic cells and tissue as oxidative stress targets in SLE}

Oxidative damage to red blood cells and leukocytes are hallmarks of oxidative stress in SLE. Lipid peroxidation, in SLE erythrocytes, and generation of $\mathrm{O}_{2}-$ and $\mathrm{H}_{2} \mathrm{O}_{2}$ in leukocytes were increased in SLE patients when compared to healthy controls (Tewthanom et al., 2008). Destroying effects of free radicals in lupus disease are apparent on the reactions with serum proteins. Oxidation makes the proteins more fragile. Modified proteins become autoantigens, and more, their presence enhances oxidative stress in serum. 4-hydroxy-2nonenal (4- HNE), which is a marker of lipid peroxidation in SLE, after binding protein forms dangerous protein adducts. The target of 4- HNE modification reported was catalase, a membrane protein of red blood cells (D'Souza et al., 2008). Hydroxyl radical binds human serum albumin. The increase in total serum protein carbonyl levels in the SLE patients was largely due to an increase in oxidized albumin (Shjekh et al., 2007).

In lupus disease, oxidative stress presents by lipid peroxidation mostly. Moreover it was discovered that lipid peroxidation influences pathogenesis of the disease. The disease activity score (SLEDAI) positively correlates with serum levels of MDA. T-lymphocyte apoptosis and MDA were positively associated with disease activity (Shah et al., 2011). MDA- modified proteins as the catalase, and SOD are targets of IgG circulated autoantibodies promoting disease development. On the other hand, SLEDAI score correlates negatively with serum antioxidant enzymes as SOD, and glutathione peroxidase (GPx) (Taysi et al., 2002 b). Auto- antibodies against plasma lipoproteins have been reported in SLE patients (Batuca et al., 2007). The study further documented incidence of antibodies toward high density lipoproteins (HDL) in patients with SLE, and identified Apo A-I as a target of oxidative damage. The incidence of auto-antibodies against lipid particles correlated with reduced activity of paraoxonase (PON), which is the most active antioxidant enzyme in lipids, and also prevents lipid peroxidation of low density lipoproteins (LDL).

\subsection{Connective cells and tissue as oxidative stress targets in SLE}

The arthritis of SLE is described as non- destructive and non- deforming. Immune complex deposits in the synovium are associated with mild inflammation and cartilage destruction is seldom severe. In SLE patients, NO and its intermediates may be mediators of inflammatory arthritis. Antibodies against 3- nitrotyrosine (3- NT) were found elevated in sera, and synovial fluid of SLE patients. Interestingly, the sera levels were much higher than in synovial fluid (Khan \& Siddiqui, 2006).

\section{Markers of oxidative stress in human autoimmune joint diseases}

A short lifetime of free radicals in body fluids restricts their direct estimation instead effects of oxygen on lipids, proteins, and nucleic acids molecules are used. There are many chemical modifiers of protein, and lipid structures, whose activity is accelerated by oxidative stress. $\mathrm{N}$-carboxymethyllysine (CML) represents a chemically modified amino acid and originates in vivo from carbohydrate as well as from lipid derived precursors. Oxidative damage to proteins is also reflected by increased levels of advanced oxidation protein 
products (AOPP), which form by the reaction between chlorinated oxidants ( $\mathrm{HOCl} / \mathrm{OCl}-)$ and proteins. AOPP are defined as dityrosine-containing cross-linked proteins. MDA is one of the end products of lipid peroxidation induced by ROS and marker of oxidative stress in lipids. 8-Hydroxy-2'-deoxyguanosine (8-OHdG) has been recognized as a biomarker of oxidative DNA damage by endogenously generated oxygen radicals. In addition, oxidative stress may be estimated by levels of enzymes like thioredoxin, a protein with reduction / oxidation active disulfide / dithiol groups in its active site. Signs of oxidative stress are apparent on cells and tissue affected by arthritis. Advanced glycation end products (AGEs), which are formed during the Maillard reaction by non-enzymatic glycation, and oxidation of proteins were detected in the synovial lining, sublining, and endothelium in RA patiens. CML showed positive immunostaining in some RA macrophages (CD68+) and T cells $(\mathrm{CD} 45 \mathrm{RO}+)$ (Drinda et al., 2002). High levels of protein carbonyl (PCO), and AGE products were found in serum of collagen - induced arthritis mice (Choi, 2007). Plasma MDA concentrations are significantly higher in RA patients (Sarban et al., 2005). An excessive degree of oxidative stress in RA patients confirm decline of protein thiol levels and lower activity of antioxidant enzymes like glutathione (GSH), GPx, and CuZn SOD in blood of these patients (Seven et al., 2008). The study by Jikimoto (Jikimoto et al., 2001) discovered elevated levels of TRX in plasma, and synovial fluid of RA patients. Plasma TRX correlated with urinary excretion of 8-hydroxy-29-deoxyguanosine (8-OHdG). Serum MDA levels were increased in SLE patients, while serum antioxidant levels were decreased in these patients what confirms oxidative stress in the pathology of SLE (Taysi et al., 2002 a).

\section{Oxidative stress in autoimmune joint diseases: Beneficial or harmful?}

The recent research describes dual role of ROS in autoimmune- joint diseases. The ROS production by the activated NOX-family (NADPH) of oxidases has a principal function throughout the priming phase of the development of autoimmune joint diseases. The NADPH oxidase- deficient knockout mice developed a serious inflammatory arthritis with extensive bone erosions and a massive osteolysis (van de Loo et al., 2003). ROS might reduce arthritis development influencing circulating inflammatory cells before they reach the joint. ROS limit $\mathrm{T}$ cell responses to self- antigens inducing their apoptosis, what inhibits disease development (Olofsson et al., 2003). Arthritis development correlates with functionality of NADPH- oxidase complex, which is determined by the neutrophil cytosolic factor 1 (Ncf 1), a phagocytic oxidase. The naturally occurring polymorphism of Ncf1 allele limiting the NADPH functionality promotes activation of arthritogenic CD4+ cells. An expansion of arthritogenic $\mathrm{T}$ cells owing to the lower activity of the NADPH- oxidase complex was observed in the DA Ncf 1 allele (Olofsson et al., 2003). An increased severity of arthritis was observed in animals with either loss of function mutations or deletions in components of the phagocyte NADPH- oxidase like the p47phox (van de Loo et al., 2003). Furthermore, the effect of NOX-derived ROS might depend on the arthritis model: in IFNgamma (INF- $\gamma$ ) enhanced imine complex arthritis, the p47phox-deficient animals showed a less severe joint destruction and decreased chondrocyte death (Lem van Lent et al., 2005).

The NADPH- oxidase- derived superoxide is not exclusive effector molecule in arthritis. Superoxide dismuthase (SOD) catalyses the dismutation of superoxide anion to oxygen and hydrogen peroxide. Three SOD enzyme isoforms have been characterized in humans. SOD I, and SOD III are copper, zinc, enzyme isoforms. SOD II is a manganese enzyme isoform. 
Whereas type I SOD is found mostly in the cytoplasm, nucleus, and intermembrane space of mitochondria, type III of SOD is extracellular. Manganese is cofactor for SOD type II, which is a mitochondrial enzyme. The enzyme is involved in the pathogenesis of inflammatory joint disease. In adjuvant model of arthritis the enzyme suppressed swelling, and retarded bone destruction (Shingu et al., 1994). An intra-articular injection of SOD significantly reduced synovitis in streptococcal wall cell (SWC)- model of arthritis. Intra- aricular injection of native SOD (bovine orgotein) produced greater clinical improvements than did intra- articular aspirin in patients with RA involving the knee (Afonso et al., 2007). Available data suggest a protective role of SOD in inflammatory joint disease. In mice that are genetically deficient in SOD III, both the severity of collagen-induced arthritis and the production of pro-inflammatory cytokines are increased. SODIII gene transferred subcutaneously or intra- articularly decreased the severity of experimental arthritis in rodents.

\section{Antioxidants as therapeutic possibilities in human autoimmune joint diseases}

\subsection{Antioxidant enzymes}

SODs exert protective effects in animal models of inflammation. In mice, genetically deficient in SOD III, both the severity of collagen- induced arthritis and the production of pro- inflammatory cytokines are increased (Ross et al., 2004). SOD III gene transfer into the knee decreased the severity of experimental arthritis in rodents. In humans, serum SOD III levels correlated negatively with disease activity. Despite conflicting results of native SOD (orgotein) in RA patients, SOD mimetics have shown beneficial effects. Until now, the most promising are nitroxide (tempol) and Mn (II) pentaazamacrocyclic ligand (M40403). In vitro, tempol diminishes hydroxyl radical production, and decreases the cytotoxic effects of hydrogen peroxide and peroxynitrite. Tempol decreased collagen- induced arthritis in rats (Cuzzocrea et al., 2001). The anti-inflammatory effects of M40403 ligand are related to superoxide elimination, and restraint of nitration of tyrosine residues in proteins. M40403 ligand diminishes the expression of adhesion molecules such as integrins or selectins decreasing influx of neutrophils to inflammatory site. M40403 ligand inhibits TNF- $\alpha$ via blocking the nuclear factor kappa $\mathrm{B}(\mathrm{NF}-\kappa \mathrm{B})$. Its beneficial effects have been reported in rats with collagen- induced arthritis (Cuzzocrea et al., 2005).

\subsection{Vitamins}

Micronutrient supplementation has been recommended to arthritic patients based on findings that the antioxidant status is very low in these patients. It has been documented that the mean synovial fluid concentrations of a-tocopherol are significantly decreased in arthritic patients compared to healthy controls. Also, levels of vitamin E in peripheral blood cell were significantly decreased in patients with active arthritis than in healthy subjects (Vasanthi et al., 2009). Concentrations of other antioxidant vitamins such as A, C are of lower order in RA and SLE patients than in normal subjects too. Based on animal studies, there is evidence that antioxidant vitamins may prevent arthritis, and increase antioxidant status. Daily oral administration of vitamin E to male arthritic rats restored levels of thiol ($\mathrm{SH}$ ) groups to pre- arthritic levels (Kheir- Eldin et al., 1992). High doses of vitamin C (1- 
$2 \mathrm{~g} / \mathrm{kg}$ body weight) applied to arthritic Lewis rats, delayed incidence of paw oedema in these rats. Histological studies revealed a decreased inflammatory cells infiltration of superficial layer of synovium, and decreased synovial SOD activity in these rats (Sakai et al., 1999). In addition, administration of rutin (vitamin P) strongly inhibited spontaneous ROS production in RA neutrophils (Ostrakhovitch \& Afanas'ev, 2001). Vitamin E exerts analgetic effects. The results from a double blind clinical trials suggested that a dose of 400-1200 mg of $\alpha$-tocopherol daily was effective with respect to various pain parameters such as pain on pressure, pain at rest, and pain on movement. The postulated analgesic properties of vitamin E seem to be correlated to vitamin E plasma concentrations. Patients with active RA supplemented with a combination of conjugated fatty acids and vitamin $\mathrm{E}$ improved their disease activity score. The diet in these patients relieved from night and activity pain, and morning stiffness (Aryaeian et al., 2009). The analgesic effect of vitamin E is independent of a peripheral anti-inflammatory action, thereby suggesting a central rather than peripheral action. Dietary antioxidant micronutrients act as scavengers of reactive oxygen radicals and may protect against free radical mediated tissue damage in an inflamed joint. Vitamin E supplemented in soyabean oil reduced anti- double- stranded DNA IgG antibodies (ChiaChien \& Bi- Fong, 2005).

\subsection{Fatty acids}

Eicosapentaenoic acid and docosahexaenoic acid (EPA and DHA respectively) exert potent antioxidant properties. Supplementation with these acids to lupus patients restored levels of antioxidant enzymes as the GPx, and SOD to baseline levels (Mohan, \& Das, 1997). Lupus autoimmune female mice fed with fish oil exhibited significantly higher liver of catalase, SOD, and GPx. The diet was shown to be beneficial against oxidative damage of hepatic tissue (Bhattacharya et al., 2003). Sera of lupus mice treated with conjugated linoleic acid (CLA) contained higher concentrations of total GSH which were negatively correlated with the levels of oxidative stress markers. Moreover, increased GSH, gammaGCL, glutathione Stransferase (GSTs), and NAD(P)H:quinone oxidoreductase (NQO1) activities were measured in liver and spleen of CLA-treated animals. The activation of detoxifying enzymes may be one of the mechanisms whereby dietary CLA down-regulates oxidative stress in lupus mice (Bergamo et al., 2007).

\section{Conclusions and future perspectives}

In all cell types, oxygen metabolism can lead to the production of reactive oxygen / nitrogen species. Reactive species are known for their dual role as both beneficial and harmful. Deleterious effects of oxidative stress on cell components (proteins, lipids, DNA) include changes in their structure, and function. On the other hand, beneficial effects of ROS/RNS involve physiological cellular responses to noxious agents, e.g., in defense against infectious agents, in a number of cellular signaling pathways and in the induction of a mitogenic response. Oxidants even protect cells against oxidative stress and re-establish or maintain redox homeostasis (Ortona et al., 2008).

Oxygen metabolism has an important role in the pathogenesis of autoimmune joint diseases. Reactive oxygen/nitrogen species are documented as mediators of synovial inflammation. Their excessive production at the site of inflammation contributes to inflammatory process 
in general, by induction of local production of chemoattractants, adhesion molecules, and pro- inflammatory cytokines. In addition, oxidative stress may contribute to the cyclic, selfperpetuating nature of autoimmune inflammation. Immune cells when "affected" by oxidants became auto- antigens intensifying auto- immune responses. Persisting autoinflammation, and oxidative stress in joint area leads to damages of connective tissue and the ECM directly or indirectly. In vitro, lipid peroxidation, ONOO-formation is associated with decreased production of type II collagen and aggrecan, and with diminished chondrocyte responses to growth factors. Moreover, ONOO- interferes with metabolism of matrix enhancing the expression of matrix degrading enzymes inhibiting the production and activity of tissue inhibiting enzymes. Hydrogen peroxide and singlet oxygen accelerate bone resorption. Level of oxidative stress in rheumatoid synovium is proportional to the levels of hypoxia and angiogenesis in the joint area.

Oxidative stress generated within an inflammatory joint can produce autoimmune phenomena and connective tissue destruction in rheumatoid synovitis (Vasanthi et al., 2009). Swelling stiffness pain in rest immobility are common symptoms of autoimmune joint diseases. Rationale of antioxidant therapy should relieve from objective complications. Polyunsaturated fatty acids (PUFA) can modulate oxidative stress and may have a role as regulators in the synthesis of antioxidant enzymes (Mohan \& Das, 1997). Arthritic patients taking these acids showed biochemical and chemical improvement. Dietary supplementation significantly decreased joint pain index. In combination with other dietary modifications modest improvement in morning stiffness and in the number of painful joints were reported. Clinical improvements were connected with anti- inflammatory effects as a decreased synthesis of leukotriens by neutrophils and lower synthesis of IL-1 $\beta$ by macrophages. Significant clinical benefit has been claimed in SLE patients given a low- fat diet with PUFA (reviewed in Darlington \& Stone, 2001). The clinical work with diets containing PUFA has clearly demonstrated their anti-inflammatory effects, but it was also shown that these effects were attributed to omega- $3(\omega-3)$ rather than $\omega-6$ PUFA. As there is no doubt about dietary fatty acids do decrease the generation of inflammatory agents, opposite results have been obtained on free radical formation. PUFA are especially potent at increasing levels of oxidative stress. On the other hand, EPA increases mitochondrial MnSOD mitochondrial activity.

The hypothesis about oxidative stress promotes arthritic process was challenged when oxidants were shown to decrease disease severity in mouse and rat arthritis models. Certain oils with an alkane structure such as phytol besides its oxidative effects protect against arthritis development. Its subcutaneous administration prevented development of pristaneinduced arthritis (Hultqvist et al., 2006). Rats treated with phytol in acute phases of pristane arthritis showed no signs of inflammation. A decrease in COMP, a measurement of ongoing cartilage destruction, was prevented during chronic phases of the disease. The efficiency of phytol in preventing arthritis was compared to methotrexate and/or etanecerpt. Etanecerpt, TNF- $\alpha$ blocker, was highly effective in reducing collagen- induced arthritis. In pristaneinduced arthritis, the preventive effects of phytol was more pronounced than that of etanecerpt. Also, in comparison to MTX, phytol was valid as a potential therapeutic agent. Concluded, ROS-promoting substances such as phytol represent a promising class of therapeutics for treatment of autoimmune joint inflammatory diseases what needs further research. 


\section{Acknowledgements}

The work was supported by VZ 0021620816 and by 262708/SVV/2011 and by CN LC 554 .

\section{References}

Abramson, S.B.; Amin, A.R.; Clancy, R.M. \& Attur, M. (2001). The role of nitric oxide in tissue destruction. Best Practice \& Research Clinical Rheumatology, Vol. 15, No.5, pp. 831-845.

Arii, K.; Kumon, Y.; Ikeda, Y; Suehiro, T. \&Hashimoto, K. (2006). Edaravone inhibits rheumatoid synovial cell proliferation and migration. Free Radic Res, Vol. 40, No. 2 , pp. 121-125.

Aryaeian, N.; Shahram, F.; Djalali, M.; Eshragian, M.R.; Djazayeri, A.; Sarrafnejad, A.; Salimzadeh, A.; Naderi, N.; Maryam, Ch. (2009). Effect of conjugated linoleic acids, vitamin $\mathrm{E}$ and thein combination on the clinical outcome of Iranian adults with active rheumatoid arthritis. International Journal of Rheumatic Diseases, Vol. 12, pp. 20-28.

Afonso, V.; Champy, R.; Mitrovic, D.; Collin, P. \& Lomri, A. (2007). Reactive oxygen species and superoxide dismutases: Role in joint diseases. Joint Bone Spine, Vol. 74, No. 4 , pp. 324- 329.

Babior, B.M. (2000). Phagocytes and oxidative stress. Am J Med, Vol. 109, No. 1, pp. 33-44.

Batuca, J.R.; Ames, P.R.J.; Isenberg, D.A. \& Delgado Aves, J. (2007). Antibodies toward high/densitz lipoprotein components inhibit paraoxonase activity in patients with systemic lupus erythematosus. Ann. N.Y.Acad. Sci. Vol. 1108, No. 1, pp. 137- 146.

Bergamo, P.; Maurano, F. \& Rossi, M. (2007). Phase 2 enzyme induction by conjugated linoleic acid improves lupus- associated oxidative stress. Free Radic Biol Med, Vol. 43, No. 1, pp. 71-79.

Bhattacharya, A. \& Lawrence, R.A. (2003). Effect of dietary n-3 and n-6 oils with and without food restriction on activity of antioxidant enzymes and lipid peroxidation in livers of cyclophosphamide treated autoimmune- prone NZB/W female mice. J Am Coll Nutr, Vol. 22, No. 5, pp. 388-399.

Billinghurst, R.C.;Dahlberg, L.; Ionescu, M., Reiner, A.; Bourne, R.; Rorabeck, C.; Mitchell, P.; Hambor, J.; Diekmann, O.; Tischesche, H.; Chen, J.; Van Wart, H.\& Poole, A.R.. (1997). Enhanced cleavage of type 11 collagen by collagenases in osteoarthritic articular cartilage. J Clin Invest, Vol. 99, No. 7, pp.1534-1545.

Biniecka, M. ; Kennedy, A.; Fearon, U. ; Ng, Ch. T.. ; Veale, D.J. \& O' Sullivan. (2009). Oxidative damage in synovial tissue is associated with in vivo hypoxic status in the arthritic joint. Ann Rheum Dis, Vol. 69, No.6 , pp. 1172- 1178.

Blanco, F. \& Lotz, M. (1994). IL-1-induced nitric oxide inhibits chondrocyte proliferation via PGE2. FASEB J, Vol. 8, pp. A365.

Blanco, F.J. ; Ochs, R.L. ; Schwarz, H. \& Lotz, M. (1995). Chondrocyte apoptosis induced by nitric oxide. Am J Pathol, Vol. 146, No. 1, pp.75-85.

Brouwer, E. ; Gouw, A.S. ; Posthumus, M.D. ; van Leeuwen, M.A. ; Boerboom, A.L. ; Bijzet, J. ; Bos, R. ; Limburg, P.C. ; Kallenberg, C.G. \& Westra J. (2009). Hypoxia inducible factor- 1- alpha (HIF- 1alpha) is related to both angiogenesis and inflammation in rheumatoid arthritis. Clin Exp Rheumatol, Vol. 27, No. 6, pp. 945-951.

Cao, M. ; Westerhausen-Larson, A. ; Niyibizi, C. ; Kavalkovich, H.I. ; Georgescu, H.I. ; Riyyo, C. F. ; Hebda, P.A. ; Stefanovic-Racic, M. \& Evans, C.H. (1997). Nitric oxide inhibits 
the synthesis of type II collagen without altering Col2A1 mRNA abundance : prolyl hydroxylase as a possible target. Biochem. J, Vol. 324, No. Pt1 , pp. 305- 310.

Chandel, N.S.; Maltepe, E.; Goldwasser, E.; Mathieu, C.E.; Simon, M.C. \& Schumacker, P.T. (1998). Mitochondrial reactive oxygen species trigger hypoxia- induced transcription. Cell Biology, Vol. 95, No. 20, pp. 11715- 11720.

Chia- Chien, H. \& Bi- Fong, L. (2005). The effects of vitamin E supplementation of autoimmune- prone New Zeland black 3 New Yeland white F1 mice fed an oxidized oil diet. Br J Nutr, Vol. 93, No. , pp. 655- 662.

Choi, E-M. (2007). Oxidative status of DBA/ 1J mice with type II collagen induced arthritis. J Appl Toxicol, Vol. 27, No.5, pp. 472- 481.

Cuzzocrea, S. ; Riley, D.P. ; Achille, P.C. \& Salvemini, D. (2001). Antioxidant therapy : A new pharmacological approach in shock, inflammation, and ischemia / reperfusion injury. Pharmacol Rev, Vol. 53, No. 1, pp. 135- 159.

Cuzzocrea, S.; Mazzon, E.; di Paola, R.; Genovese, T.; Muia, C.; Caputi, A.P. (2005). Synergistic interaction between methotrexate and a superoxide dismutase mimetic: pharmacologic and potential clinical significance. Arthritis Rheum, Vol. 52, No. pp. 3755-3760.

Darlington, L.G \& Stone, T.W. (2001). Antioxidants and fatty acids in the amelioration of rheumatoid arthritis and related disorders. Br J Nutr. Vol. 85, No. , pp. 251- 269.

Del Carlo Jr, M. \& Loeser, R.F. (2002). Nitric oxide- mediated chondrocyte cell death requires the generation of additional reactive oxygen species. Arthritis $\mathcal{E}$ Rheumatism, Vol. 46, No. 2, pp/ 394- 403.

Drinda, S. ; Franke, S. ; Canet, C.C ; Petrow, P. ; Bräuer, R. ; Hüttich, C. ; Stein, G. \& Hein, G. (2002). Identification of the advanced glycation end products Ncarboxymethyllysine in the synovial tissue of patients with rheumatoid arthritis. Ann Rheum Dis, Vol. 61, No. 6, pp. 488-492.

D' Souza, A. ; Kurien, B. T. ; Ridgers, R. ; Shenoi, J. ; Kurono, S. ; Matsumo, H. ; Hensley. ; Nath, S.K. \& Scofield, R.H. (2008). Detection of catalase as a major protein target of the lipid peroxidation product 4-HNE and the lack of its genetic association as a risk factor in SLE. BMC Medical Genetics, Vol. 9, pp.62.

Eggleton, P. ; Wang, L. ; Penhallow, J. ; Crawford, N. \& Brown, K.A. (1995). Differences in oxidative response of subpopulations of neutrophils from healthy subjects and patients with rheumatoid arthritis. Ann Rheum Dis, Vol. 54, No. 11, pp. 916- 923.

El Benna, J. ; Hayem, G. ; My-Chan Dang, P. ; Fay, M. ; Chollet- Martin, S. ; Elbim, C. ; Meyer, O. \& Gougerot- Pocidalo, M-A. (2002). NADPH oxidase priming and p47phox phosphorylation in neutrophils from synovial fluid of patients with rheumatoid arthritis and spondylarthropathy. Inflammation, Vol. 26, No. 6, pp. 273- 278.

Galleron, S.; Borderie, D.; Ponteziere, C.; Lemarechal, H.; Jambou, M.; Roch- Arveiller, M.; Ekindjan, O.G. \& Calls, M.J. (1999). Reactive oxygen species induce apoptosis of synoviocytes in vitro. Alpha tocopherol provides no protection. Cell Biol Int, Vol. 23, No. 9, pp. 637- 642 .

Giatromanolaki, A.; Sivridis, E.; Maltezos, E.; Athanassou, N.; Papazoglou, D.; Gatter, K.C.; Harris, A.L. \& Koukourakis, M.I. (2003). Upregulated hypoxia inducible factor- $1 \alpha$ and $-2 \alpha$ pathway in rheumatoid arthritis and osteoarthritis. Arthritis Res Ther, Vol. 5, No. 4, pp. R193- R201. 
Gibson, J.S.; Milner, P.I.; White, R.; Fairfax, T.P.A. \& Wilkins, R.J. (2008). Oxygen and reactive oxygen species in articular cartilage: modulators of ionic homeostasis. Pflugers Arch - Eur J Physiol, Vol. 455, No. 4, pp.563-573.

Hadjigogos, K. (2003). The role of free radicals in the pathogenesis of rheumatoid arthritis. Panminerva Med, Vol. 45, No. 1, pp. 7-13.

Henrotin,Y. E.; Bruckner, P.; Pujol, J.P.L. (2003). The role of reactive oxygen species in homeostasis and degradation of cartilage, OsteoArthritis and Cartilage, Vol. 11, No. 10, pp. 747-755.

Hickery, M.S. \& Bayliss, M.T. (1998). Interleukin-1 induced nitric oxide inhibic sulphation of glycosaminoglycan chaos in human articular cartilage chondrocytes. Biochimica et Biophysica Acta, Vol. 1425, No.2 , pp. 282- 290.

Hiran, T. S.; Moulton, P.J. ; Hancoc, J.T. (1997). Detection of superoxide and NADPH oxidase in porcine articular chondrocytes. Free Radical Biology \& Medicine, Vol. 23, No. 5, pp. 736-743.

Hitchon, C. A. \& El- Gabalawy, H.S. (2004). Oxidation in rheumatoid arthritis. Arthritis Res Ther, Vol. 6, No. 6, pp. 265- 278.

Hollander, A.P.; Corke, K.P.; Freemont, A.J. \& Lewis, C.E. (2001). Expression of hypoxiainducible factor 1 a by macrophages in the rheumatoid synovium. Implications for targeting genes to the inflammaed joint. Arthritis \& Rheumatism, Vol. 44, No. 7, pp. 1540-1544.

Hovatta, I.; Juhila, J.; Donner, J. (2010). Oxidative stress in anxiety and comorbid disorders. Neurosci Res, Vol. 68, No. 4, pp.261-275.

Hultqvist, M.; Olofsson, P.; Gelderman, K. A.; Holmberg, J.; Holmdahl, R. (2006). A New Arthritis Therapy with Oxidative Burst Inducers. Plos Medicine, Vol 3, No. 9, pp.1625-1636.

Jikimoto, T.; Nishikubo, Y.; Kanagawa, S.; Morinobu, S.; Saura, R.; Miyuno, K,; Kondo, S.; Toyokuni, S.; Nakamurad, H.; Yodoi, J. \& Kumagai, S. (2001). Thioredoxin as a biomarker for oxidative stress in patients with rheumatoid arthritis. Mol Immunol, Vol. 38, No. 10 ,pp. 765- 772.

Ji-Yeon, S.; Jang- Hee, H.; Hyung-Sik, K.; Inpyo, Ch.; Sang-Deok, L.; June- Kyu, L.; Jeong-Ho, S.; Jae-Heun, L. \& Gang- Min, H. (2000). Methotrexate suppresses the interleukin-6 induced generation of reactive oxygen species in the synoviocytes of rheumatoid arthritis. Immunopharmacology, Vol. 47, No. , pp. 35- 44.

Kennett, E.C. \& Davies, M.J. (2009). Glycosaminoglycans are fragmented by hydroxy L carbonate and nitrogen dioxide radicals in a site- selective manner: implications for peroxynitrite- mediated damage at sites of inflammation. Free Radical Biology $\mathcal{E}$ Medicine, Vol. 47, No. 4 , pp. 389- 400.

Khan, F. \& Siddiqui, A.A. (2006). Prevalence of anti- 3- nitrotyrosine antibodies in the joint synovial fluid of patients with rheumatoid arthritis, osteoarthritis and systemic lupus erythematosus. Clin Chim Acta, Vol. 370, No. 1-2, pp. 100-107.

Kheir- Eldin, A.A; Hamdy, M.A.; Motawi, T.K.; Shaheen, A.A. \& Abd El Gawad, H.M. (1992). Biochemical changes in arthritic rats under the influence of vitamin E. Agents Actions, Vol. 36, No. 3-4, pp. 300-305.

Kurz, B.; Steinhagen, J. \& Schünke, M. (1999). Articular chondrocytes and synoviocytes in a co-culture system: influence on reactive oxygen species- induced cytotoxicity and lipid peroxidation. Cell Tissue Res, Vol. 295, No. 3, pp. 555-563. 
Lark, M.W.; Bayne, E.K.; Flanagan, J.; Harper, C.F.; Hoerner, L.A.; Hutchinson, N.I.; Singer, I.I.; Donatelli, S,A.; Weidner, J.R.; Williams,H.R.; Mumford, R.A.; Lohmander, L.S. (1997) Aggrecan degradation in human cartilage. Evidence for both matrix metalloproteinase and aggrecanase activity in normal, osteoarthritic, and rheumatoid joints. J Clin Invest, Vol. 100, No. , pp.93-106.

Lem van Lent, P.; Nabbe, K.C.; Blom, A.B.; Sloetjes, A.; Holthuysen, A.E.M.; Kolls, J.; Van De Loo, F. A.J.; Holland, S.M. \& Van Den Berg, W.B. (2005). (NADPH)-oxidase- driven oxygen radical production determines chondrocyte death and partly regulates metalloproteinase- mediated cartilage matrix degradation during interferon- $\gamma$ stimulated immune complex arthritis. Arth Res E Ther, Vol. 7, No. 4, pp. 2005.

Lo, Y. C.L.; Wong, J.M.S. \& Cruz, T.F. (1998). Reactive oxygen species mediate cytokine activation of c- Jun NH2- terminal kinases. J Biol Chem, Vol. 271, No. 26, pp. 1570315707.

Lushchak, V. (2011). Adaptive response to oxidative stress: Bacteria, fungi, plants and animals. Comp Biochem Physiol, Vol. , No. pp. 175- 190.

Mattey, D.L.; Nixon, N.; Alldersea, J.E.; Cotton, W.; Fryer, A.A.; Zhao, L.; Jones, P. \& Strange, R.C. (1993). Alpha, mu and pi class glutathione S- transferases in human synovium and cultured synovial fibroblasts: effects of interleukin-1 alpha, hydrogen peroxide and inhibition of eicosanoid synthesis. Free Radic Res Commun, Vol. 19, No. 3, pp. 159- 617.

Maurice, M.M.; Nakamura, H.; van der Voort, E.A.; van Vliet, A.I.; Staal, F.J.; Tak, P.P; Breedveld, F.C.\& Verweij, C.L. (1997). Evidence for the role of an altered redox state in hyporesponsiveness of synovial T cells in rheumatoid arthritis. J Immunol, Vol. 158, No.3, pp. 1458- 1465.

Miesel, R.; Kurpisz, M. \& Kröger, H. (1996). Suppression of inflammatory arthritis by simultaneous inhibition of nitric oxide synthase and NADPH oxidase. Free Radical Biology \& Medicine, Vol. 20, No. 1, pp. 75-81.

Mohan, I.K. \& Das, U.N. (1997). Oxidant stress, anti-oxidants and essential fatty acids in systemic lupus erythematosus. Prostag Leu Ess Fatty Acid, Vol. 56, No.3, pp. 193- 198.

Monboisse, J.C. \& Borel, J.P. (1992). Oxidative damage to collagen. EXS, Vol. 62, pp. 323327.

Newkirk, M.M.; Goldbach- Mansky, R.; Lee, J.; Hoxworth, J.; McCoy, A,; Yarboro, Ch.; Klippel, J. \& El- Gabalawy, H.S. (2003). Advanced glycation end-product (AGE)damaged IgG and IgM autoantibodies to IgG AGE in patients with early synovitis. Arthritis Res Ther, Vol. 5, No. 2 , pp. R82- R90.

Olofsson, P.; Holmberg, J.; Tordsson, J.; Lu, S.; Akerström, B. \& Holmdahl, R. (2003). Positional identification of $\mathrm{Ncf} 1$ as a gene that regulates arthritis severity in rats. Nat Genet, Vol. 33, No. 2 , pp. 25-32.

Ortona, E.; Margutti, P.; Matarrese, P.; Franconi, F.; Malorni, W. (2008). Redox state, cell death and autoimmune diseases: a gender perspective. Autoimmun Rev, Vol. 7, No. 7, pp. 579- 584.

Ostrakhovitch, E.A. \& Afanas' ev, L.B. (2001). Oxidative stress in rheumatoid arthritis leukocytes: suppression by rutin and other antioxidants and chelators. Biochemical Pharmacology, Vol. 62, No. 6, pp. 743-746. 
Regan, E.A.; Bowler, R.P. \& Crapo, J.D. (2008). Joint fluid antioxidants are decreased in osteoarthritic joints compared to joints with macroscopically intact cartilage and subacute injury. Osteoarthritis \& Cartilage, Vol. 16, No. 4 , pp. 515- 521.

Ross, A.D.; Banda, N.K.; Muggli, M.; Arend, W.P.(2004). Enhancement of collagen induced arthritis in mice genetically deficient in extracellular superoxide dismuthase. Arthritis Rheum, Vol. 50, No. , pp. 3702- 3711.

Sakai, A.; Hirano, T.; Okayaki, R.; Okimoto, N.; Tanaka, K. \& Nakamura, T. (1999). Largedose ascorbic acid administration suppresses the development of arthritis in adjuvant- injected rats. Arch Orthop Trauma Surg, Vol. 119, No. 3-4, pp. 121- 126.

Sarban, S.; Kocyigit, A.; Yazar, M. \& Isikan, U.E. (2005). Plasma total antioxidant capacity, lipid peroxidation, and erythrocyte antioxidant enzyme activities in patients with rheumatoid arthritis and osteoarthritis. Clin Bioch, Vol. 38, No.11, pp. 981- 986.

Seven, A.; Güzel, S.; Aslan, M. \& Hamuryudan, V. (2008). Lipid, protein, DNA oxidation and antioxidant status in rheumatoid arthritis. Clin Bioch, Vol. 41, No. 7-8, pp. 538543.

Shah, D.; Kiran, R.; Wanchu, A. \& Bhatnagar, A. (2010). Oxidative stress in systemic lupuys erythematosus: relationship to Th1 cytokine and disease activity. Immunol Lett, Vol. 129, pp. 7-12.

Shah, D.; Wanchu, A. \& Bhatnagar, A. (2011). Interaction between oxidative stress and chemokines: Possible pathogenic role in systemic lupus erythematosus and rheumatoid arthritis. doi: 10. 1016/ j.imbio. 2001. 04. 001.

Shankar, J.; Thippegowda, P.B. \& Kanum, S.A. (2009). Inhibition of HIF-1a activity by BP-1 ameliorates adjuvant induced arthritis in rats. Biochemical and Biophysical Research Communications, Vol. 387, No. 2 , pp. 223- 228.

Shingu, M.; Takahashi, S.; Ito, M.; Hamamatu, N.; Suenaga, Y.; Ichibangase, Y.; Nobunaga, M. (1994). Anti- inflammatory effects of recombinant human manganese superoxide dismuthase on adjuvant arthritis in rats. Rheumatol Int, Vol. 14, No. 2, pp. 77-81.

Shejkh, Z.; Ahmad, R.; Shejkh, N.; Ali, R. (2007). Enhanced recognition of reactive oxygen species damaged human serum albumin by circulating systemic lupus erythematosus autoantibodies. Autoimmunity, Vol. 40, No. 7, pp. 512- 520.

Schett, G.; Tohidast- Akrad, M.; Steiner, G. \& Smolen, J. (2001). Commentary. The stressed synovium. Arthritis Res, Vol. 3, No. 2, pp. 80-86.

Schneider, N.; Mouithys- Mickalad, A.L.; Lejeune, J.- P.; Deby-Dupont, G.P.; Hoebeke, M. \& Serteyn, D.A. (2005). Synoviocytes, not chondrocytes, release free radical after cycles of anoxia/ re-oxygenation. Biochimical and Biophysical Research Communications, Vol. 334, No. , pp. 669- 673.

Stefanovic- Racic, M.; Mollers, M.O.; Miller, M.A.\& Evans, C.H. (1997). Nitric oxide and proteoglycan turnover in rabbit articular cartilage. J Orthop Res, Vol. 15, No. 3, pp. 442- 449.

Šimelyte, E.; Boyle, D. L. \& Firestein, G.S. (2004). DNA mismatch repair enzyme expression in synovial tissue. Ann Rheum Dis, Vol. 63, No. 12, pp. 1695-1699.

Vasanthi, P.; Nalini, G.; Rajasekhar, R. (2009). Status of oxidative stress in rheumatoid arthritis. Int J Rheum Dis, Vol. 12, No., pp. 29- 33. 
Taysi, T.; Gul, M.; Saris, R.A.; Akcay, F. \& Bakan, N. (2002 a). Serum oxidant/ antioxidant status of patients with systemic lupus erythematosus. Clin Chem Lab Med, Vol. 40, No. 7, pp. 684- 688.

Taysi, T.; Polat, F.; Gul, M.; Saris, R.A. Bakan, N. (2002 b). Lipid peroxidation, some extracellular antioxidants, and antioxidant enzymes in serum of patients with rheumatoid arthritis. Rheumatol Int, Vol. 21, No. 5, pp. 200- 204.

Tewthanom, K.; Janwityanuchit, S.; Totemchockchyakarn, K. \& Panomvana, D. (2008). Correlation of lipid peroxidation and glutatione levels with severity of systemic lupus erythematosus: A pilot study from single center. J Pharm Pharmaceut Sci, Vol. 11, No. 3, pp. 30-34.

Van de Loo, F.A.J.; Bennink, M.B.; Arntz, O.J.; Smeets, R.L.; Lubberts, E.; Joosten, L.A.B.; van Lent, P.L.E.M.; Coenen- de Roo, Ch. J.J.; Cuzzocrea, S,; Segal, B.H.; Holland, S.M. \& van den Berg, W. B. (2003). Deficiency of NADPH oxidase components p47phox and gp91phox caused granulomatosus synovitis and increased tissue destruction in experimental arthritis model. Am J Pathol, Vol. 163, No. 4, pp. 1525- 1536.

Vasanthi, P.; Nalini, G. \& Rajasekhar, G. (2009). Status of oxidative stress in rheumatoid arthritis. Int J Rheum Dis, Vol. 12, No. 1, pp. 29- 33.

Yoshida, S.; Katoh, T.; Tetsuka, T.; Uno, K.; Matsui, N. \& Okamoto, T. (1999). Involvement of thioredoxin in rheumatoid arthritis: its costimulatory roles in the TNF- $\alpha$ - induced production of IL-6 and IL-8 from cultured synovial fibroblasts. Immunol, Vol. 163, No. 1, pp. 351-358. 


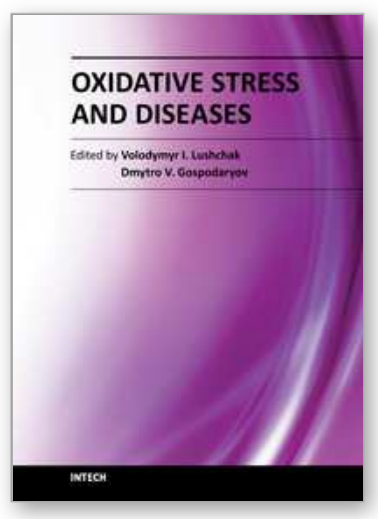

\author{
Oxidative Stress and Diseases \\ Edited by Dr. Volodymyr Lushchak
}

ISBN 978-953-51-0552-7

Hard cover, 610 pages

Publisher InTech

Published online 25, April, 2012

Published in print edition April, 2012

The development of hypothesis of oxidative stress in the 1980s stimulated the interest of biological and biomedical sciences that extends to this day. The contributions in this book provide the reader with the knowledge accumulated to date on the involvement of reactive oxygen species in different pathologies in humans and animals. The chapters are organized into sections based on specific groups of pathologies such as cardiovascular diseases, diabetes, cancer, neuronal, hormonal, and systemic ones. A special section highlights potential of antioxidants to protect organisms against deleterious effects of reactive species. This book should appeal to many researchers, who should find its information useful for advancing their fields.

\title{
How to reference
}

In order to correctly reference this scholarly work, feel free to copy and paste the following:

Martina Škurlová (2012). Oxidative Stress in Human Autoimmune Joint Diseases, Oxidative Stress and Diseases, Dr. Volodymyr Lushchak (Ed.), ISBN: 978-953-51-0552-7, InTech, Available from:

http://www.intechopen.com/books/oxidative-stress-and-diseases/oxidative-stress-in-human-autoimmune-jointdiseases

\section{INTECH}

open science | open minds

\section{InTech Europe}

University Campus STeP Ri Slavka Krautzeka 83/A 51000 Rijeka, Croatia Phone: +385 (51) 770447

Fax: +385 (51) 686166 www.intechopen.com

\section{InTech China}

Unit 405, Office Block, Hotel Equatorial Shanghai No.65, Yan An Road (West), Shanghai, 200040, China 中国上海市延安西路65号上海国际贵都大饭店办公楼 405 单元 Phone: +86-21-62489820

Fax: +86-21-62489821 
(C) 2012 The Author(s). Licensee IntechOpen. This is an open access article distributed under the terms of the Creative Commons Attribution 3.0 License, which permits unrestricted use, distribution, and reproduction in any medium, provided the original work is properly cited. 